\title{
A POÉTICA DO ICONOTEXTO: UM ENTRE-LUGAR PARA TEXTO E IMAGEM EM PATHÉ-BABY, DE ANTÓNIO DE ALCÂNTARA MACHADO
}

\author{
POETICS OF THE ICONOTEXT: IN-BETWEEN PLACE FOR TEXT \\ AND IMAGE IN PATHÉ-BABY, BY ANTÓNIO DE ALCÂNTARA \\ MACHADO
}

\author{
Lucas da Cunha ZAMBERLAN ${ }^{1}$
}

\begin{abstract}
Resumo: Este trabalho objetiva analisar as inter-relações entre imagem e texto no livro Pathé-Baby (1926), de António de Alcântara Machado. Para tanto, foi recrutado um aporte teórico oriundo dos estudos sobre a intermidialidade, a partir do conceito de iconotexto proposto por Liliane Louvel em $A$ descrição "pictural": por uma poética do iconotexto (2006) e Nuanças do pictural (2012). Considerando os resultados obtidos, avaliam-se, de maneira geral, as potencialidades imagéticas proporcionadas pelo discurso verbal e, em particular, os variados graus de picturalidade existentes nas descrições da obra, o que caracteriza, de forma intrincada, o florescimento de uma poética do iconotexto na narrativa.
\end{abstract}

Palavras-Chave: Pathé-Baby. António de Alcântara Machado. Iconotexto. Intermidialidade. Modernismo.

Abstract: This work aims to analyze the interrelations between image and text in the book Pathé-Baby
(1926) by António de Alcântara Machado. Therefore, we selected a theoretical contribution from the
studies on intermidiality, based on the concept of iconotext proposed by Liliane Louvel in Poetics of
the iconotext (2006) and Nuances du pictural (2012). Considering the results, the imaginary potential
provided by verbal discourse and in particular the varying degrees of pictoriality in the descriptions of
the work are evaluated in a general way, which characterizes, in an intricate way, the flowering of a
poetics of the iconotext in the narrative.

Keywords: Pathé-Baby. António de Alcântara Machado. Iconotext. Intermidiality. Modernism.

Pathé-Baby é o livro de estreia do escritor modernista António Alcântara Machado, publicado em 1926. O título constitui-se em alusão à popular câmera cinematográfica de 9,5mm produzida pela Pathé Brothers Company, empresa de máquinas e produção cinematográfica, além de ser a produtora fonográfica de maior projeção no cenário mundial no final do século XIX e início do século XX.

Lançado um ano após o autor voltar da Europa, Pathé-Baby apareceu, originalmente, na coluna semanal do Jornal do Comércio, com o subtítulo "Panoramas Internacionais". Os textos relatam a trajetória do autor no Velho Mundo, registrando cidades da França (Paris),

\footnotetext{
${ }^{1}$ Doutor em Letras - Estudos Literários - pelo Programa de Pós-Graduação em Letras da Universidade Federal de Santa Maria (UFSM). E-mail: lucaszamberlan@yahoo.com.br 
Inglaterra (Londres), Itália (Roma, Milão, Florença, Veneza, Pisa, Lucca, Siena, Nápoles, Perugia e Assis), Portugal (Lisboa) e Espanha Madrid, Barcelona, Sevilha, Córdoba, Granada e Toledo) com uma visão subjetiva engendrada pela sua sensibilidade de artista e estetizada por uma técnica narrativa cinematográfica que se formata e se molda à projeção visual de uma câmera Pathé-Baby.

A complexidade estrutural da obra, naturalmente, borra os limites tradicionais delimitados pelos gêneros literários, trazendo à baila especificidades narrativas que se presentificam no romance, por exemplo, como as narrações de eventos concomitantes e descrições pormenorizadas de paisagens. Ao mesmo tempo, ocorre, no conjunto dos capítulos, uma flagrante aproximação de Pathé-Baby com as crônicas de viagens, milenares na literatura, mas com franca expansão no início do século $\mathrm{XX}$, haja visto a relativa popularização das viagens transoceânicas. Ademais, ainda é possível estabelecer um vínculo dos fragmentos com o conto, seja pela brevidade narrativa, seja pela autossuficiência semântica existente entre as partes da obra.

A partir disso, pelo apelo visual que permeia sua construção, há uma evidente demarcação de elementos pictóricos que, mediados pelas técnicas cinematográficas, legitimam sua presença na narrativa e prestam-se a uma análise mais atenta. Com isso, este trabalho objetiva analisar as imbricações entre imagem e texto existentes em Pathé-Baby a partir da perspectiva teórica de Liliane Louvel, buscando identificar diferentes graus de picturalidade no discurso literário para, dessa forma, compreender a emergência de uma poética do iconotexto, resultado desse fenômeno híbrido em que palavra e imagem se encontram.

As nítidas evidências pictóricas de Pathé-Baby, impulsionadas pela interferência do cinema como representação de ordem visual, incitam reflexões que apontam para rumos teóricos convergentes, encontrando na intermidialidade uma base analítica que sustenta premissas teóricas e diálogos de valência diversa. Cada fragmento do livro carrega um emaranhado de formas, luzes, movimento e ação paisagística que exacerba pela via da descrição, combinando o ritmo da narrativa com imagens múltiplas que se sucedem ao sabor da "montagem" literária. 
Liliane Louvel (2006), em A descrição pictural: por uma poética do iconotexto, trabalha o conceito de iconotexto ao defini-lo como a zona transitória entre texto e imagem, estabelecendo sentido para este entre-lugar intermidiático, presente em romances, novelas e contos que preconizam a visualidade como forma de expressão. Assim, a sua existência está condicionada às descrições picturais, nas quais há invariavelmente a convocação da imagem pelo texto, realizada através de ferramentas que a linguagem literária oferece para que essa relação aconteça. Em Nuanças do pictural (2012), Louvel lista esses instrumentos de associação verbo-picturais, nomeando-os de marcadores:

\footnotetext{
Citemos rapidamente esses marcadores da descrição pictural: o léxico técnico (cores, nuanças, perspectiva, glacis, verniz, formas, camadas, linha, etc.); a referência aos gêneros picturais (natureza-morta, retrato, marinha); o recurso aos efeitos de enquadramentos; a colocação de operadores de abertura e de fechamento da descrição pictural (dêiticos, enquadramentos textuais como os encaixes nas narrativas, a pontuação, o branco tipográfico, a repetição do motivo "era"); a colocação de focalizadores e operadores de visão; a concentração na história de dispositivos técnicos que permitem ver; o recurso às comparações explícitas "como em um quadro" (LOUVEL, 2012, p. 49, grifo da autora).
}

Em Pathé-Baby, seja pela tentativa de imitar a narrativa fílmica - e seus inumeráveis artifícios visuais -, seja pela aproximação mais direta com a pintura e com a fotografia ocorre um povoamento considerável destes marcadores. Em "Lisboa", em um pequeno trecho, Alcântara Machado reúne alguns deles:

\footnotetext{
jardim da europa

Cais do Sodré. Monumento aos homens do mar. Os barcos de pesca, atracados, com os mastros nus, são árvores desfolhadas, secas, oscilantes.

O Século e o Diário de Notícias comemoram com desenhos, fotografias, rojões rimados, o sétimo aniversário da batalha de Lys. Nove de Abril. Dia embandeirado. Pretexto para os portugueses relembrarem mais uma vez o passeio triunfal das cinco quinas pelo mundo, a grandeza dos Gama e heroísmo dos Albuquerque. Portugal de hoje: saudade geográfica do de ontem (MACHADO, 2002, p.31-32, grifos do autor).
}

O fragmento principia com um título que faz alusão ao modo como Portugal é chamado, antevendo por um tropos, a perífrase, a natureza da capital e como ela é vista no mundo: o jardim da Europa. Em seguida, o narrador anuncia o Cais do Sodré, bairro tradicional de Lisboa que se situa em frente ao Tejo e que, portanto, carrega consigo uma forte simbologia em relação à época das navegações. Essa primeira inferência é realçada pela segunda frase, "monumento aos homens do mar" em que considera o local como uma espécie de memorial coletivo do povo português que vê no rio e no cais uma ligação com o passado de glórias. 
No poema "O Tejo é mais belo que o rio que corre pela minha aldeia", o também modernista Fernando Pessoa/Alberto Caeiro problematiza a carga histórica e simbólica do rio Tejo, criando um sujeito-lírico que o compara a um rio desconhecido de sua aldeia:

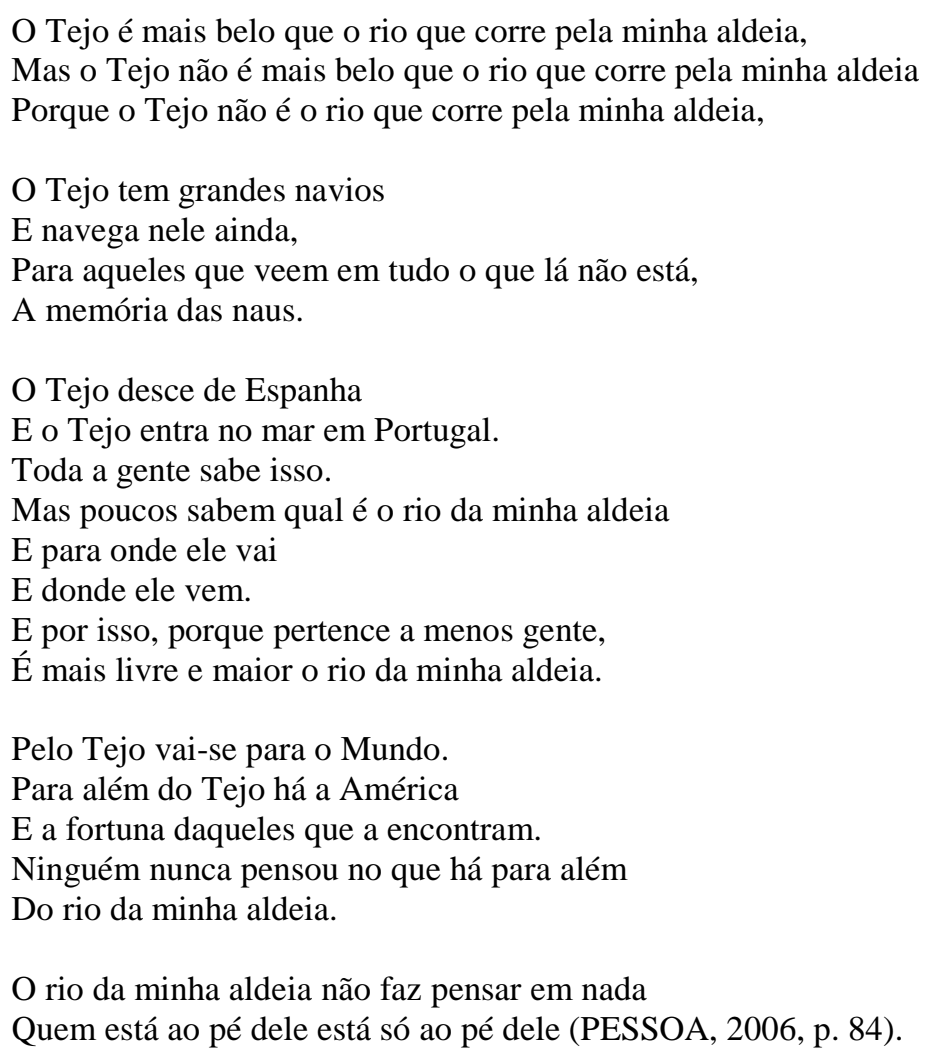

No âmbito da discussão sobre a identidade nacional portuguesa e sua correlação com o período dos descobrimentos, a segunda estrofe do poema é conclusiva. O Tejo carrega consigo a "memória das naus", fazendo com que qualquer pessoa, ao olhá-lo, sinta a presença dos desbravadores portugueses in absentia. Com isso, confirma-se a visão lusitana, pregada por Pessoa, de rememorar o passado na observação do rio. Alcântara Machado apreende a mesma visão e a explora de maneira visual.

A terceira frase do fragmento de "Lisboa" configura-se, com propriedade, como um grande exemplo de descrição pictural: “os barcos de pesca, atracados, com os mastros nus, são árvores desfolhadas, secas, oscilantes". No trecho, o narrador estabelece uma metáfora, unindo o campo visual de barcos de pesca à imagem de árvores secas. Esse recurso, tido por Louvel como um marcador pictural, repete-se dessa forma - e também como comparação em diversos trechos da narrativa, como em: "Das janelas da torre, os telhados das casas são papoulas crescidas na paisagem verde" (MACHADO, 2002, p. 36); “A estrada é um traço de giz" (MACHADO, 2002, p. 36); "Escuridão de túneis. Pequenos castelos, cercados por 
parques e gramados. Macieiras perfiladas como soldados" (MACHADO, 2002, p. 43); "As avenidas são doze bocas de asfalto que comem gente e veículos, vomitam gente e veículos" (MACHADO, 2002, p. 49); “A estrada de asfalto é um risco de lápis cortando o campo verde. Paris ficou para trás. Na bruma” (MACHADO, 2002, p. 65); “As casas são pedras brancas encravadas nas encostas (MACHADO, 2002, p. 22); “Ao longe, macieiras em flor são velhinhas de cabelos brancos imóveis na relva esmeralda” (MACHADO, 2002, p. 65); “Ao longe, Capri é uma nuvem preta boiando" (MACHADO, 2002, p. 149); "Coventry Street lateja como um vaso cardíaco" (MACHADO, 2002, p. 77); e "Sob as folhagens da Rambla, a multidão se estende como um tapete" (MACHADO, 2002, p. 179, grifos nossos).

$\mathrm{Na}$ sequência, Alcântara Machado lança mão de outro marcador, "a concentração na história de dispositivos técnicos que permitem ver”. Os jornais O Século e Diário de Notícias celebram o sétimo aniversário da batalha de La Lys, da Primeira Guerra Mundial, com desenhos e fotografias, compondo, pela combinação de mídias próprias do jornal, uma evocação da imagem pela palavra. Não é dado ao leitor de Pathé-Baby a faculdade de ver as fotos, mas, na caracterização das mídias apontadas e na temática militar, pode-se abrir espaço para a realização de um campo intermidiático que só pode ser preenchido pelo iconotexto.

Ao final, fica a reflexão própria de um modernista brasileiro que procurava, assim como seus companheiros de ofício, desvincular-se da colonização cultural (linguística, inclusive) imposta durante séculos por Portugal. Uma vez que os portugueses, no seu ponto-de-vista, sentem as "saudades geográfica do de ontem", o Brasil e principalmente São Paulo, ao contrário, projetam-se para o futuro e harmonizam-se com os novos tempos do Pós-Primeira Guerra. Sevcenko (2003), timbra, com aspectos geográficos impressionantes, a dimensão do fenômeno urbano de São Paulo:

\footnotetext{
De acordo com o primeiro censo, realizado em 1872, quando a cidade já estava sob o efeito do grande surto cafeeiro em terras paulistas, sua população era de 19.347 pessoas. Número que se elevou a 64.934 habitantes no censo seguinte, em 1890. No início do século XX, a cidade já contava com 270 mil moradores, segundo o levantamento de 1908. Cifra essa que dobrou em 1920, atingindo 578 mil pessoas e praticamente tornou a dobrar em 1934, para alcançar o pico de 1 milhão e 120 mil habitantes. O que equivale a dizer que no período de 62 anos, 1872 a 1934, São Paulo configurou uma prodigiosa taxa de crescimento populacional da ordem de $5689 \%$, ou, posto de outra forma, cresceu numa escala de 6,77\% ao ano. Esses números pareciam justificar plenamente o refrão ufanista de que "São Paulo é a cidade que mais cresce no mundo" (SEVCENKO, 2003, p. 108-109).
}

Há também outro capítulo, em Pathé-Baby, de extrema relevância na evidenciação das descrições picturais presentes no texto. Em "Londres", ao captar o passeio dos ingleses pelo 
Hyde Park, Alcântara Machado, mais uma vez, serve-se de marcadores bem definidos para alcançar um efeito estético revestido de elementos visuais:

\footnotetext{
hyde-park

O verde é macambúzio. Só há flores nos chapéus das mulheres. Elegantes de sapatos amarelos e cartola. Bulldogs enfatuados. O esfarrapado no banco lê os anúncios do The Evening Standart.

Pela King Road se desenrola a cauda dos automóveis. Passo de parada, os cavalos dão importância aos cavaleiros [...] Há sujeitos tristes, tristes de cachimbo apagado.

Em torno do pavilhão de chá, as mesinhas verdes reúnem gente contente. A orquestra toca o Tea for two para ninguém ouvir.

No gramado escovado, vultos sentados jogam o sério com o céu. Cachorros bem educados cumprimentam-se de longe. A tarde (a bola da criança bate na careca do pastor) cai como uma folha (MACHADO, 2002, p. 81-82, grifos do autor).
}

Uma análise do primeiro parágrafo apenas seria suficiente para comprovar a riqueza pictórica do excerto. Na primeira frase, há a utilização da cor verde como um substantivo algo incomum - além de sujeito da oração, completada pelo verbo de ligação e predicativo do sujeito. A intenção é definir, em termos de visualidade, a tonalidade da cor, de baixa saturação e pouca expressividade, que encontrará afinidade no comportamento formal e circunspecto dos ingleses e seus animais que compõem a cena.

Isso quer dizer, em uma análise que avalia o "tom" do texto, que o autor se vale de uma cor (o verde macambúzio) para predicar não só os matizes cromáticos da grama do Hyde Park, mas proeminentemente os costumes do povo londrino, no seu habitual e reconhecido estilo sóbrio. Dessa maneira, todo o trecho contamina-se pela coloração, ditando as ações do público em conformidade com o "tom" definido logo no início. As expressões "bulldogs enfatuados", "cavalos dão importância aos cavaleiros", "Há sujeitos tristes, tristes de cachimbo apagado", "vultos sentados jogam o sério" e "cachorros bem educados cumprimentam-se de longe" demonstram isso.

Depois da primeira frase, o narrador descreve acontecimentos variados, "montando" os fragmentos curtos em imagens permeadas de cor, já que homens elegantes calçam sapatos amarelos e as mulheres usam chapéus com flores. Além disso, as cartolas (pretas) completam, com os cachorros, a cena primaveril de maio, enquanto um "esfarrapado" observa os anúncios do jornal The Evening Standart, assim como outro homem, de "Lisboa", interpretava os desenhos e fotografias nos jornais portugueses.

No segundo parágrafo, a Pathé-Baby deixa, por instantes, o parque a fim de registrar a rua e a convivência característica da época entre automóveis em movimento e cavalos 
parados. Afora isso, homens tristes fumam cachimbo apagado. No retorno ao parque, as mesinhas, também verdes, do pavilhão de chá reúnem gente contente e insensível ao som da orquestra, que executa o jazz Tea for two. Para encerrar, pessoas sentadas no gramado (verde) escovado "jogam o sério" com o céu (azul?). E a última frase agrava a sensação de simultaneidade, pois o narrador interrompe a descrição pictural, no trecho entre aspas, e finaliza com uma comparação (a tarde cai como uma folha) que expande o grau de visibilidade do texto escrito.

Entretanto, por mais que se identifique a presença da poética do iconotexto nos capítulos de Pathé-Baby, uma pergunta torna-se necessária: existe uma maneira de quantificar, de forma gradativa, essas ocorrências? Com o intuito de definir um estatuto de saturação visual, Louvel (2012, p. 50) elenca sete níveis, listados em ordem crescente, que demonstram os graus que um texto literário pode atingir no diálogo com o universo pictural: o efeito quadro, a vista pitoresca, a hipotipose, os quadros-vivos, o arranjo estético, a descrição pictural e, por fim, a écfrase.

Salvo algumas exceções, como é o caso dos quadros-vivos, com relações profundas com o teatro; do arranjo estético, próprio ao texto convencional de ficção; e da écfrase, os substratos visuais destacados pela autora aparecem em Pathé-Baby. Os trechos de "Lisboa" e "Londres", por exemplo, encaixar-se-iam perfeitamente na primeira categoria de Louvel, o efeito quadro:

O efeito quadro, resultado do surgimento na narrativa de imagens-pinturas, produz um efeito de sugestão tão forte que a pintura parece assombrar o texto mesmo na ausência de qualquer referência direta, seja à pintura em geral, seja a um quadro em particular [...] o efeito acontece no nível da recepção, quando de repente o leitor tem a impressão de ver um quadro (LOUVEL, 2012, p. 50, grifos da autora).

Esse efeito quadro é perceptível, na verdade, em praticamente todos os capítulos da narrativa. $\mathrm{O}$ fato ocorre pela natureza compositiva do livro que, a todo momento, recruta a linguagem literária e suas especificidades para convocar imagens estáticas ou em movimento, como em um filme mudo. No entanto, no caso do efeito quadro, Louvel enfatiza o primeiro grupo de imagens, ou seja, as imóveis, promovendo a suspensão de ações e aproximando-se definitivamente da pintura, como no trecho de "Las Palmas", em que os acontecimentos se paralisam em prol da materialização verbal do efeito quadro: 
Cem metros sim, cem metros não, gravuras de folhinhas. Rua estreita, de lajedos grandes, que sobe em caracol. Rosas nas fendas dos muros. Um menino montado num burrico orelhudo de pelo arrepiado. Uma velhota. Outra velhota.

A cidade afasta-se do mar e trepa nos morros. As casas são pedras brancas encravadas nas encostas.

Renques verdes de bananeiras alegres. Chaminés. Quintalejos (MACHADO, 2002, p. 22).

No capítulo "Barcelona", na representação de uma tourada, a despeito da movimentação intensa do toureiro, do animal e dos espectadores, o efeito ocasionado pela descrição com características cinéticas acarreta, paradoxalmente, a construção visual de um quadro. Entretanto, não uma tela convencional, delimitada pelos parâmetros clássicos, de perspectiva consagrada e utilização de cores tradicionais. No lugar desses elementos, o trecho poderia ser filiado à arte modernista de pintores vanguardistas, como Picasso, Léger, Delaunay, Braque ou Boccioni, que buscavam, incansavelmente, a captação de dinamismo inerente à vida europeia da época do Modernismo:

As patas do touro negro golpeiam a terra. Borboletar de capas. O cavalo de olhos vendados recebe a chifrada, sacode as patas dianteiras no alto, cai destripado. $\mathrm{O}$ touro cola-se contra outro [...].

O touro abaixa a cabeça diante do homem azul que caminha. E pula como um autômato. A capa resvala sobre os chifres.

- Olé!

Vai e vem diante do focinho espumante.

- Olé!

O toucador é um pião roçando a nuca peluda.

- Olé!

$\mathrm{O}$ delírio levante vinte e cinco mil entusiasmos. As palmas sacodem o anfiteatro ondeante (MACHADO, 2002, p.180-181).

O narrador preocupa-se, nessa passagem como em muitas outras, em descrever um cenário, recrutando, pela verve linguística, os sentidos do narrador. Embora adote um estilo sincopado, ele não despreza os componentes sinestésicos, valorizando, pela economia vocabular, um conjunto de sensações que destacam a cena e ressaltam o "efeito quadro".

A visão é acionada pela ação plástica do touro, do homem que o enfrenta, da multidão entusiasmada e também pelo jogo cromático entre o negro do touro, o azul das roupas do toureiro e o vermelho da sua capa; o tato é despertado pelos verbos que sugerem movimentos suaves, como o resvalar da capa e o roçar do toucador; já a audição revela-se nos gritos de olé e nas palmas. É necessário ressaltar, em adição, que esse pequeno trecho destaca o uso de uma metáfora (O toucador é um pião roçando a nuca peluda) e uma símile (E pula como um autômato), recursos que emprestam expressividade ao texto literário. 
O segundo nível de iconotexto, as vistas pitorescas, capta, através da linguagem verbal, cenas de rua, marcadas por acontecimentos incomuns que surpreendem pela originalidade e andamento inóspito. Geralmente, elas impõem-se como um convite à criação pictórica, devido à sua natureza única e abundantemente visual.

Os capítulos mais representativos de Pathé-Baby, em geral, distanciam-se da visão pitoresca, justamente pelo lugar onde Alcântara Machado se encontra. Os ambientes que ele frequenta, os lugares que ele busca, as ruas pelas quais ele peregrina fogem do padrão pitoresco e enfatizam a convivência urbana de turistas e locais das grandes cidades europeias. Tentando inverter a lógica da viagem para Europa-Brasil, e não Brasil-Europa, o poeta Blaise Cendrars, por exemplo, em suas passagens pelo Brasil nessa mesma época, deve ter encontrado muito mais paisagens pitorescas nas suas andanças pela América do Sul que Alcântara Machado no Velho Mundo.

Alguns trechos, contudo, aparecem na contramão das outras passagens. Em "Nápoles", o narrador descreve uma cena de rua típica da região da Campânia, sem mencionar grandes interferências de personagens estrangeiros na composição, aproximando-se, assim, de um retrato genuíno e peculiar da cidade:

\footnotetext{
Cozinhas ao ar livre. Confusão de mostras de sapatos, de tabaco, de roupas, de verdura. Cheiro azedo de comida popular. Humildade pestilenta. Crianças nuas pulando em poças de água verde. Mulheres amamentando. Burricos. Fedor de aglomeração pública. Panelas de macarrão. Mixórdia de cortiço. Mãos magras, abaixadas catando pedaços de pão e tocos de cigarro. A Traviata fanhosa (tararitarará-tarari) de um realejo torto. Flores de papel. Imagens santas. Tascas [...].

Dois olhos lindos de miséria. Gestos obscenos. Pilhas de parmesão e grana. Blasfêmias compridas. Bandeirinhas tricolores. Cartazes. OMMAGGIO A MARIA S. S, DEL CARMINE! VIVA MARIA S. S. DEL CARMINE! Em baixo a carvão: Morra!

Uma velhinha corcunda dançando a tarantela ao som de uma orquestra de assovios de garotos. Caçada desesperada de piolhos na soleira de uma porta. Algazarra e moscas. Pitoresco.

Saudade de creolina (MACHADO, 2002, p. 146-147, grifo nosso).
}

Percebe-se, no trecho, por meio da sintaxe entrecortada e do jogo de palavras, as mudanças de perspectiva, a coexistência de ações, o atordoante convívio social e o apelo sinestésico dos sons, dos cheiros e evidentemente das imagens que concorrem para armar um quadro cultural sui generis da cidade italiana. Com isso, o narrador faz com que o leitor passeie pela gastronomia, pela música, pela religião e pelo comércio de Nápoles, imiscuindose aos costumes populares do lugar e compreendendo a dinâmica das relações interpessoais de seus habitantes. A vista pitoresca é emoldurada, no final, pela própria menção ao termo 
"pitoresco". Ele, ao afirmar isso textualmente, confirma o viés da descrição e a sua relação com a teoria apresentada por Louvel.

Em "Paris", ocorre algo semelhante. Embora não tenha um fechamento tão adequado como em "Nápoles", o fragmento contribui visualmente de uma maneira diferente. O subcapítulo se chama Fête-foraine e, pelo nome, faz referência a uma das feiras de rua mais populares da França até hoje. Na época, proporcionava todo tipo de diversões a crianças e adultos, concentrando-se, preponderantemente, em espetáculos circenses, carrosséis de dois andares, atrações cênicas, sessões de fotografia ao ar livre e reprodução cinematográfica de filmes mudos.

Após descrever o passeio dos operários e suas famílias pelo parque, a Pathé-Baby literária de Alcântara Machado se volta para a cena pitoresca de uma apresentação de um homem-morcego:

\footnotetext{
- Venez voir l'HOMME CHAUVE-SOURIS!

$\mathrm{Na}$ frente da barraca a pintura é um monstro com pernas e rosto de homem, mas asas e orelhas de morcego. Ao lado da borradela sensacional, o furunculoso recebe o franco e afasta a cortina.

Os curiosos ficam de pé olhando a caixa. O tipo, de dentro da caixa, ergue a tampa com a cabeça. Mostra bem a careca. Depois sorri.

E desaparece

A velhinha de guarda-chuva sai indignada, dizendo que é exploração.

- Venez voir l'HOMME CHAUVE-SOURIS! Un franc! Un franc! Seulement! Assim de gente! (MACHADO, 2002, p. 58-59).
}

Depois do anúncio feito pelo personagem/apresentador, o narrador transpõe para a linguagem verbal a "borradela sensacional" do homem-morcego: "monstro com pernas e rosto de homem, mas asas e orelhas de morcego". O trecho é finalizado com a encenação um tanto teatral do homme chauve-souris, a fúria das senhoras com a exploração de um franco e o sucesso de público com o espetáculo pitoresco.

O fato curioso é que, nesse período, o cinema-mudo também vinha apelando, via expressionismo, para realização de filmes que valorizavam a criação de personagens monstruosos que chamavam a atenção pelos aspectos incomuns, como $O$ Gabinete do Doutor Caligari, de 1920, além de Dr. Mabuse e Nosferatu, ambos de 1922, e M, o vampiro de Dusseldorf, de 1931. Os atores, nessas produções, geralmente utilizavam máscaras, maquiagens e figurinos que acentuavam o caráter assombroso que predominava nas cenas. Além disso, esses filmes também demonstram uma importante influência estética de formas e cores advindas da pintura expressionista, acentuando a picturalidade como um aspecto relevante do período, tanto no cinema como na literatura (CÁNEPA, 2012, p. 55-65). 
O próximo grau de saturação pictural levantada por Louvel é a hipotipose. A principal diferença entre os níveis visuais efeito quadro e a hipotipose é o dinamismo paisagístico, constante no segundo e rarefeito no primeiro. Dessa maneira, na comparação entre os dois modelos, Pathé-Baby, como filme mu(n)do, representa melhor a hipotipose na sua tentativa bem realizada de registrar uma Europa pulsante e cosmopolita.

Louvel reforça, insistentemente, o caráter móvel da hipotipose: "ela não imobiliza o texto, espacializando-o, como de costume, mas o temporaliza. A hipotipose seria, então, um exemplo de narração descritiva, um lugar de forte concentração de figuras (LOUVEL, 2012, p. 54).

Em uma passagem de "Roma", a temporalização do texto e a concentração de figuras realmente consagram um "exemplo de narração descritiva":

\footnotetext{
Na Stazione di Termini as hordas desembarcam em ordem. A invasão quotidiana de Roma pelos bárbaros da Agência Cook, da American Express, das peregrinações católicas.

Enfileiram-se os batalhões basbaques. Empunham bandeirinhas. Ostentam medalhas. Trocam dinheiro (muito).

Vêm ver as ruínas e o Papa [...]

Focalizando kodaks ou berrando litanias, as hordas vão-se [...]

Antes de partir, na Fontana de Trevi deixam o soldo propício que garante a volta a Roma (MACHADO, 2002, p. 169).
}

Nesse capítulo, como em outros já analisados, o autor monta um quadro paisagístico de ações simultâneas que prima pela velocidade, representando a cidade em movimento. $\mathrm{Na}$ principal estação de trens da cidade, a Stazioni Termini - que passaria, na década seguinte, por uma reestruturação estética pautada pelas linhas futuristas de Angiolo Mazzoni recepciona os "bárbaros" organizados pela Agência Cook (pioneira a criação de pacotes turísticos) que invadem a Roma moderna em busca das "peregrinações católicas".

O cosmopolitismo acentuado da invasão é caracterizado pelos inúmeros turistas que desembarcam, enfileiram-se, empunham bandeirinhas, ostentam medalhas, trocam dinheiro, focalizam kodaks, berram litanias, vão-se e deixam dinheiro na Fontana di Trevi. Na descrição, a abundância de verbos - sempre no presente do indicativo - indica que tudo é plasticidade cinética, transformando a paisagem ininterruptamente. O entusiasmo dos visitantes dinamiza a cena e a temporaliza, para utilizar a palavra escolhida por Louvel.

A menção, já bastante repetida, das kodaks apreende o cenário em instantâneos que reforçam o imaginário visual da narrativa, misturando algo que em Pathé-Baby é bastante comum: as intersecções entre a literatura, a pintura e a fotografia. Ao decompor a paisagem, 
sintaticamente, em frases que compreendem o todo pela sua união, cada sentença não deixa de significar, de forma metafórica, uma fotografia registrada. Sob este ponto-de-vista, as hipotiposes também se aproximam das descrições de natureza jornalística de Alcântara Machado que procura, objetivamente, compor ações, por meio de palavras, da forma mais fotográfica possível.

Süssekind (2006) aborda essa questão quando analisa a produção literária do início do século XX e estende a António de Alcântara Machado a "kodakização" da paisagem, em Pathé-Baby, selecionando um fragmento da obra. A passagem, de fato, eterniza, em instantâneos sucessivos, a cidade de Paris, e enforma, literariamente, a técnica da máquina, recorrendo a uma prosa de feição concisa e entrecortada. O componente inóspito do trecho é o registro de um inglês que manipula uma Kodak. Dessa maneira, as barreiras entre a forma e o conteúdo se dissipam em prol de um objetivo estético bem definido:

Place de l'Étoile. Em torno do Arco do Triunfo magotes de automóveis giram. As avenidas são doze bocas de asfalto que comem gente e veículos, vomitam gente e veículos. Insaciáveis.

Ruído. Pó. E gente. Muita gente. O soldado apita, levanta o seu bastão, e a circulação para para que se possam passar, tranquilamente, a ama e seu carrinho. Duas costureirinhas que tagarelam. A família que vai bocejar nos bancos do Bois. Um maneta vendendo alfinetes. Gargalhadas de uma loura de olheiras verdes. A Kodak de um inglês. Um casal de namorados. Israelitas ostentando a roseta da legião de Honra. Monóculos. Paris que passa (MACHADO, 2002, p. 49, grifos nossos).

No tocante às descrições picturais, a teórica concebe o termo como um coroamento de todos os graus anteriores, indicando sua natureza múltipla e essencialmente visual. Nesse sentido, Pathé-Baby, também pelo seu conjunto estético que envolve diversos marcadores visuais e grau de saturabilidade imagética elevado, mostra-se repleto dessas descrições, instituindo-se como um produto cultural que exemplifica muito bem a presença do iconotexto, em acordo com as contribuições intelectivas de Louvel.

\section{Considerações finais}

Pathé-Baby é, antes de qualquer classificação possível, uma obra que reúne, pela especificidade dos seus recursos verbais, uma série de possibilidades analíticas que permitem compará-la às outras artes e mídias, sobretudo as visuais. A relação com o cinema é, via de regra, a mais corriqueira, pois o próprio nome da obra remete a uma câmera, sugerindo, desde a sua apresentação, a configuração de um filme feito com palavras. 
Entretanto, a potência visual evocada pelas nuanças da linguagem modernista de Alcântara Machado suscita investigações teóricas de outras naturezas, na qual a pintura ocupa um plausível lugar de destaque. Assim, este trabalho, pela via da intermidialidade, examinou os recursos linguísticos utilizados pelo autor, com o fito de estabelecer vínculos profícuos entre as "artes irmãs".

Dessa maneira, a proposta de níveis de picturalidade apresentada por Louvel revelou valiosa contribuição, pois clarificou, sobremaneira, a dimensão visual alcançada pela obra. Com exemplos categóricos de efeito quadro, passando pela vista pitoresca, a hipotipose e finalmente a descrição pictural, Pathé-Baby manifesta-se, pela abundância de marcadores picturais, como um produto cultural marcado por uma expressividade sui generis. Essa carga de expressão singular deve-se, predominantemente, pelo casamento que envolve palavra e imagem, ou seja, pela emergência do entre-lugar entre ambos: a poética do iconotexto.

\section{Referências}

CÁNEPA, Laura Loguercio. Expressionismo alemão. In: MARCARELLO, Fernando (org.) História do cinema mundial. São Paulo: Editora Papirus, 2012.

LOUVEL, Liliane. A descrição "pictural”: por uma poética do iconotexto. In: ARBEX, Márcia (org.) Poéticas do Visível: ensaios sobre a escrita e a imagem. Belo Horizonte: Faculdade de Letras da UFMG, Programa de Pós-Graduação em Letras: Estudos Literários, 2006.

Nuanças do pictural. In: DINIZ, Thaïs Flores Nogueira (Org.). Intermidialidade e estudos interartes: desafios da arte contemporânea. Tradução de Márcia Arbex. Belo Horizonte: Editora UFMG, 2012.

MACHADO, António de Alcântara. Pathé-Baby: Edição fac-similar comemorativa dos 80 anos da Semana de Arte Moderna (1922-2002). Belo Horizonte/Rio de Janeiro: Livraria Garnier, 2002.

PESSOA, Fernando. Fernando Pessoa: antologia poética. Porto Alegre: Leitura XXI, 2006.

SEVCENKO, Nicolau. Orfeu estático na metrópole: São Paulo, sociedade e cultura nos frementes anos 20. São Paulo: Companhia das letras, 2003.

SÜSSEKIND, Flora. O cinematógrafo de letras: literatura, técnica e modernização no Brasil. São Paulo: Companhia das Letras, 2006. 